\title{
Significações de um Personagem de Desenho Animado no Espaço Escolar: Um Estudo Sobre Gênero na Educação Infantil
}

\author{
Meanings of a Cartoon Character in the Space of School: A Study on \\ Gender in Early Childhood Education
}

\author{
Significados de un Personaje de Dibujos Animados en el Espacio \\ Escolar: Un Estudio sobre Género en la Educación Infantil
}

\author{
Juliana Lopes Garcia Correio \\ Prefeitura Municipal de Londrina, Brasil \\ jusly_lopes@yahoo.com.br \\ Carlos Toscano \\ Universidade Estadual de Londrina, Brasil \\ ctoscano@uel.br
}

\section{Resumo}

Neste trabalho, apresentamos parte dos dados obtidos em uma pesquisa, cujo objetivo foi investigar como emergem as questões de gênero produzidas por crianças no espaço escolar em uma turma de Educação Infantil, da rede municipal de Londrina/PR. A pesquisa foi realizada apoiada na perspectiva histórico-cultural de Vygotsky, e nos estudos de Bakhtin e Voloshinov. A partir da análise da situação "O Celular", conclui-se: questões de gênero já estão presentes na sala de aula nessa etapa da escolaridade e, ao compartilharem suas significações de gênero, as crianças, em geral, reproduzem os padrões sociais hegemônicos em acordo com a configuração desse espaço e, por vezes, estranham quando colegas não o levam em consideração.

Palavras-Chave: Espaço escolar; Educação Infantil; Gênero; Perspectiva Histórico-Cultural.

\section{Abstract}

In this article, we present some of the data gathered in a research whose objective was to investigate the emergence and characterization of the gender issues produced in the space of school, in an Early Childhood Education class from a municipal school in Londrina/Pr. The research was conducted according to Vygotsky's historical-cultural perspective, as well as to the studies of Bakhtin and Voloshinov. From the analysis of the situation called "The Cellphone", we came to the conclusion that gender issues are already present in classroom at this stage of schooling and that, when sharing their meanings of gender, children in general reproduce the hegemonic social patterns, in accordance with the actual configuration of this space, and sometimes they find it strange when their colleagues do not take it into consideration.

Keywords: School Space; Early Childhood Education; Gender; Historical-Cultural Perspective.

\section{Resumen}

En este trabajo presentamos algunos de los datos obtenidos en una investigación cuyo objetivo fue investigar cómo emergen las cuestiones de género producidos por los niños y niñas en la escuela en una clase de educación infantil de la red municipal de Londrina / Pr. La investigación se llevó a cabo a través de la perspectiva histórico-cultural de Vigotski, y los estudios de Bakhtin e Voloshinov. A partir del análisis de la situación "O Celular" se concluye que las cuestiones de género ya están presentes en el aula y que los niños y niñas, al compartir sus signifiaciones de género, en general reproducen los padrones sociales hegemónicos de acuerdo con la configuración 
Significações de um personagem de desenho

animado no espaço escolar: um estudo sobre

gênero na Educação Infantil

de este espacio y, a veces, se estrañan cuando sus colegas no lo tienen en cuenta.

Palabras-Clave: Espacio Escolar; Educación Infantil; Género; Perspectiva Histórica-Cultural.

\section{Introdução}

A Educação Infantil é um espaço organizado a partir de certa concepção educacional, visando determinado objetivo. Segundo o Referencial Curricular para Educação Infantil, o trabalho realizado na Educação Infantil é promovido por meio das relações estabelecidas entre professor/criança e criança/criança, mediados pedagogicamente, tendo em vista o acesso aos conhecimentos da realidade social e cultural, a fim de atingir o objetivo de propiciar o desenvolvimento infantil (BRASIL, 1998).

Segundo Oliveira (2011), a criança reconhece e atribui significações ao espaço escolar, avaliando intenções e valores que considera ser-lhes próprios. As crianças que frequentam a Educação Infantil atribuem significações a esse espaço a partir das relações que estabelece com as pessoas envolvidas naquele contexto. Ainda de acordo com essa autora (2011, p.198), o espaço "[...] constitui expressão de um sistema social com suas rotinas, relações, ideologias, etc. É esse sistema que prescreve a função de um espaço físico-social e as pessoas que podem utilizar, o que podem fazer e com quem".

Junckes e Silva (2009) compreendem que o espaço escolar é mais do que o um local onde se trabalha com os conhecimentos ou que prepara para o trabalho, pois as práticas vividas cotidianamente no espaço escolar são aprendizados. "Assim, o espaço escolar é complexo, é tanto produtor de significados como é também produzido por eles, assim como a ação educativa é [...]" (p. 151).

Desse modo, considera-se que a instituição infantil é um espaço permeado pelas relações, ideologias e significações presentes na comunidade onde se localiza, apresentando significações próprias desse espaço, visto que são determinadas pessoas que ocupam o mesmo. Para Junkes e Silva (2009), diferentes grupos de pessoas podem vivenciar o espaço escolar de maneiras muitos distintas.

A instituição infantil, enquanto um espaço físico-social, aborda diversas questões que fazem parte das relações sociais, entre elas as relações de gênero. Desta forma, a intervenção do outro frente a essa questão acontece mesmo que não o faça intencionalmente. Portanto, é necessário investigar e refletir sobre como as questões de gênero são tratadas na instituição infantil, em especial, na relação entre as crianças.

O modo como professores e alunos tratam o gênero, segundo Felipe (2001), pode estar pautado na naturalização das diferenças entre masculino e feminino, visto que os comportamentos de meninas e meninos são vistos como 'naturais' ou como parte integrante de uma 'essência' masculina ou feminina.

A naturalização das distinções de gênero ocorre, pois as diferenças referentes ao masculino e ao feminino se sustentaram por longa data em um discurso que naturalizava essas diferenças, postulando um padrão présocial de papéis, funções, comportamentos e modo de sentir. Desse modo, as diferenciações entre homem e mulher pautavam-se na distinção física entre ambos, determinando biologicamente toda e qualquer diferença entre $\mathrm{o}$ masculino $\mathrm{e}$ feminino.

Para superar o determinismo biológico que baseava as diferenças entre homem e mulher e que sustentava desigualdades, tabus 
e preconceitos, o discurso feminista focou o aspecto social da constituição humana. Foi nesse contexto que, segundo Scott (1990), surgiu o termo gênero em contraposição a termos como sexo, referentes à distinção física entre homem e mulher.

Com o conceito de gênero, pretendia-se destacar que as diferenças entre homem e mulher são construídas socialmente, marcadas histórica e culturalmente, ou seja, "[...] as expectativas que temos em relação a homens e mulheres, meninos e meninas são construídas numa determinada cultura e num determinado tempo histórico" (FELIPE, 2001, p. 65).

No processo educativo, nos diversos contextos sociais, o que inclui a escola, gênero é uma categoria de análise constitutiva do sujeito e, portanto, presente nas relações sociais, sendo reproduzido e transformado ao longo de tais processos. Por meio da educação, o sujeito internaliza os significados em torno do masculino e do feminino se apropriando dos elementos culturais do grupo em que está inserido.

As questões de gênero podem emergir nas diversas situações no contexto escolar, e as que emergem em um determinado contexto escolar são distintas de outro e, no mesmo contexto, gênero pode emergir de maneiras diferentes, pois as práticas culturais de um determinado grupo social, que permeiam as interações estabelecidas no espaço escolar, não estão prontas ou acabadas, mas em constante processo de ressignificação.

Nas relações que estabelece, a criança percebe que as diferenças entre meninos e meninas vão além da questão física e, em seu contexto social, vai aprendendo normas que regem os comportamentos entre homens e mulheres. De modo que, segundo Nunes e Silva (2006), a criança descobre a significação das diferenças sexuais entre meninos e meninas e suas respectivas formas sociais.
Na escola, desde a Educação Infantil, por meio das relações sociais, as próprias crianças, entre si, mostram constantemente significados do que é ser menina ou menino, do que é aceitável, ou não, muitas vezes reproduzindo padrões que sustentam desigualdades, estereótipos e preconceitos referentes a gênero.

Esses parâmetros, como todos os demais pertencentes a uma sociedade, são construídos socialmente ao longo da história e apresentados, inicialmente, pelos adultos a partir do momento em que a criança nasce, sendo posteriormente incorporados e postos em circulação pelas próprias crianças, nas suas interações, nos demais espaços sociais, incluída a escola.

\section{Gênero e a Perspectiva Histórico-Cultural}

Compreender gênero enquanto uma construção social, carregado de significados produzidos histórica e socialmente, permitenos afirmar que, dentro dos contextos culturais, por meio das relações estabelecidas, os significados em torno do masculino e do feminino são reproduzidos e também transformados.

Desde que nasce a criança entra em contato com os significados de masculino e de feminino, nesse sentido, podemos considerar, segundo Pino (1993), que a criança nasce num universo social-cultural, constituído de produções culturais e de seres humanos, ou seja, um universo significativo e, portanto, cognoscível e comunicável. A apropriação desse universo define o conteúdo do processo de constituição da criança.

A apropriação desse universo sociocultural, não é direta, mas mediada, o que pressupõe a criação e utilização de signos, pois,

$\mathrm{O}$ que distingue os homens dos animais, do ponto de vista 
psicológico, é a SIGNIFICAÇÃO, isto é, a criação e a utilização de signos, de sinais artificiais. Signo por excelência, a palavra, na sua especificidade, constitui a interface do social e do individual, do público e do privado, enquanto se configura como atividade (produto $\mathrm{e}$ produção) humana nos níveis intermental (comunicação, interação social) e intramental (representação, cognição) (SMOLKA, 1993, p. 8).

Dessa forma, a significação emerge no processo de interação social. Bakhtin privilegia, segundo Smolka (1993, p. 9), "[...] teórica e metodologicamente, as relações dialógicas como lugar de análise e produção de significação". Ainda de acordo com a autora, ao conceber a linguagem como interação e como constitutiva da cognição e do conhecimento, ganha destaque a peculiaridade da palavra que reflete e refrata a realidade histórico-cultural:

Esse modo de conceber a linguagem possibilita circunscrever e articular aspectos diferenciados da dinâmica discursiva como objeto e lugar de investigação: a linguagem como prática social em funcionamento, a enunciação como produção histórica e acontecimento singular (SMOLKA, 2000, p. 58).

As trocas verbais, enquanto produção e utilização de signos, que se faz pela palavra, e que por sua vez, ganha vida no enunciado, estrutura-se a partir da situação social mais imediata, ou seja, o enunciado está diretamente vinculado à vida em si, e ao meio social mais amplo, que constitui o conjunto das condições de vida de uma determinada comunidade linguística (BAKHTIN; VOLOSHINOV, 2002).
$\mathrm{O}$ enunciado pressupõe a interação com o outro, isto é, quando se fala, fala-se a alguém. Nesse sentido, o enunciado é produzido tendo em vista a interação entre indivíduos socialmente organizados, de modo que a palavra dirige-se a um interlocutor e varia dependendo a quem ela é direcionada, por exemplo, se é a uma pessoa do mesmo grupo social ou não, se esta for superior ou inferior, se estiver ligada ao locutor por laços mais ou menos estreitos. Além do falante e do interlocutor, o enunciado, ainda, pressupõe um terceiro participante o "herói": o que ou o quem da fala.

O enunciado concreto sempre une os participantes da situação comum como coparticipantes os quais compartilham o horizonte espacial; a unidade visível; o conhecimento e compreensão comum da situação, e a avaliação comum dessa situação. A partir desses elementos, é possível compreender o presumido, de modo que o enunciado compreende a parte percebida ou realizada em palavras e a parte presumida, sendo que apenas os pontos nos quais estamos todos unidos podem se tornar a parte presumida de um enunciado, e quanto mais amplo for o horizonte global e seu correspondente grupo social, mais constante se tornam os fatores presumidos.

$\mathrm{O}$ enunciado é fundamentalmente social e objetivo, sendo composto da unidade material, por exemplo, um local, ou objeto e da unidade das condições reais de vida, que geram uma comunidade de julgamentos de valor presumido, entendido como atos sociais regulares e essenciais - assim cada enunciado é um etimema social objetivo, como uma 'senha' conhecida apenas por aqueles que pertencem ao mesmo campo social, uma pessoa ignorante do contexto pragmático imediato não compreenderá estes enunciados.

Segundo Bakhtin e Voloshinov (1976), sempre que um julgamento básico de valor é 
verbalizado e justificado, nós podemos estar certos de que ele já se tornou duvidoso, deixou de organizar a vida e perdeu conexão com as condições existenciais do grupo.

É o julgamento de valor que determina a própria seleção do material verbal e a forma do todo verbal, sendo transmitido pela entonação. A comunhão de julgamentos básicos de valor presumidos constitui a tela sobre a qual a fala humana desenha os contornos da entonação.

Nesse sentido, a entonação expressiva transmite a apreciação social que serve para orientar a escolha e a distribuição dos elementos mais carregados de sentido da enunciação. Toda enunciação compreende uma orientação apreciativa, por isso, nesse processo, cada elemento contém ao mesmo tempo um sentido e uma apreciação.

A entonação estabelece um elo forte entre o discurso verbal e contexto extraverbal e só pode ser compreendida profundamente quando estamos em contato com os julgamentos de valor presumido por um dado grupo social. Tanto quanto a entonação, o gesto, incluindo a mímica como gesticulação facial, se impregna de uma relação forte e viva com o mundo externo e com o meio social, transmitindo também o julgamento de valor.

Assim, a partir das questões teóricas elucidadas nesse ponto, apresentamos nesse artigo parte dos dados obtidos com a pesquisa, tendo como ponto central os enunciados produzidos pelas crianças no processo de interação que aconteceu no cotidiano escolar, durante a realização de atividades livres propostas pela professora da turma nos espaços escolhidos por ela.

\section{o Contexto e a Metodologia da Pesquisa}

A pesquisa foi realizada num espaço institucional de educação, um Centro Municipal de Educação Infantil, está localizado no interior do estado do Paraná, com uma turma com vinte crianças que completaram quatro anos durante aquele ano. A opção em realizar a pesquisa com crianças de quatro anos está pautada na compreensão de que entre dois e três anos a criança começa a tomar consciência da significação das diferenças sexuais entre meninos e meninas e suas respectivas formas sociais (NUNES; SILVA, 2006).

Além das descobertas realizadas pela criança dessa faixa etária sobre as diferenças sexuais e sociais entre meninos e meninas, consideramos também que nessa idade a fala da criança está mais desenvolvida e que os elementos que pôde apreender do seu contexto social e cultural são mais vastos que aos dois ou três anos, de modo que ela pode expressar suas significações sobre gênero com maior clareza, por meio de suas brincadeiras e enunciados.

A pesquisa de campo foi realizada em quatorze encontros, no período da tarde. A cada dia foi observado o cotidiano da turma no espaço da sala de aula, sendo feito pela pesquisadora um diário de campo com breves anotações durante as observações, com a finalidade de, ao fim de cada dia, subsidiar a produção de uma descrição das situações ocorridas na sala de aula. Além do diário de campo, foi feita a gravação dos acontecimentos em sala de aula ou no ambiente escolhido pela professora para a realização das atividades do dia, sendo filmadas e registradas as atividades do referido dia, segundo o planejamento da professora.

Durante as filmagens, a intenção da pesquisadora era somente acompanhar a relação entre as crianças, ou seja, observar sem se envolver nas situações registradas. No entanto, em alguns momentos os participantes dos episódios, se dirigiram à pesquisadora para mostrar brinquedos, fazer perguntas, pedir auxilio na resolução de 
conflitos, sendo nesses casos, inevitável sua participação ainda que pontual e restrita, conforme se verá adiante.

Posteriormente, a pesquisadora assistiu às filmagens com o intuito de produzir um texto que relatasse os acontecimentos do dia para posterior análise, focalizando as situações que envolvessem questões de gênero. Os nomes das crianças, assim como das professoras, não foram citados, sendo usados nomes fictícios para se referir aos participantes dessa pesquisa.

As situações foram descritas buscando relatar as falas das crianças, que foram transcritas. Além delas, foram analisados também os gestos e as posturas, ou seja, toda a forma de expressão dos participantes envolvidos em sentido amplo.

No contexto em que as falas são analisadas, buscamos levar em conta que os enunciados estão permeados por julgamentos de valor, gerado pela situação social imediata e transmitidos por meio da entonação. Nesse sentido, foi importante perceber a entonação, nos enunciados dos participantes da pesquisa, sendo isso possível somente pela inserção da pesquisadora nesse contexto. Além da entonação o gesto também transmite os julgamentos de valor, desse modo, outro aspecto relevante a ser considerado ao analisar o enunciado, foi o gesto.

Para esse artigo, selecionamos o episódio 'O celular' cuja nomeação objetivou destacar o objeto que gerou questões sobre gênero para algumas crianças da turma, no momento da escolha de brinquedos durante uma atividade livre.

\section{Descrição e Análise dos Dados}

As crianças pegaram os brinquedos que trouxeram de casa e do baú da sala. A professora também trouxe aparelhos celulares, deixando-os sobre uma mesa permitindo que cada criança escolhesse um para brincar.

Eduarda, segurando uma boneca aproximou-se de Mariana, que lhe mostrou um celular que estava segurando. Em seguida Eduarda deslocou-se para o outro lado da sala ao encontro de Marcos, no caminho, enquanto caminhava, ela fez uma cara de espanto, e gritou: "Ah"!

Aproximando-se de Marcos, Eduarda disse com tom de indignação: "Oh Marcos, (olhou para trás onde estava Mariana) ela pego, é, o celular de Ben Dez, (com cara de espanto levou a mão na boca) o de menino".

A Eduarda virou-se para trás olhando para a Mariana e ficando ao lado de Marcos, colocou a mão sobre o ombro do colega o levando até Mariana.

Ao aproximarem-se de Mariana, que estava sentada no chão brincando com outras crianças, Eduarda disse para Marcos com tom de indignação, que ficou olhando para Eduarda sem dizer nada: "Do Ben Dez, oh. Olha lá! Mas essa muié”.

A Eduarda olhou para trás e ao ver a pesquisadora disse: "Oh tia, sabia que a, que ela (apontando o dedo para a Mariana) uso o celular de, que a Mariana uso, é a Mariana uso o celular do Ben Dez do menino".

A pesquisadora apenas reiterou: "Do Ben Dez". ${ }^{1}$

Eduarda confirmou: "É".

A pesquisadora perguntou: "De quem é o celular do Ben Dez"?

Vanessa, que estava passando entre a pesquisadora e a Eduarda, respondeu junto com Eduarda: "Do menino".

A pesquisadora devolveu a pergunta: "Do menino"?

Vanessa passou e Eduarda respondeu: "Porque ela não... ela não pode usa, é celular de Ben Dez, ela não pode (balançou a cabeça indicando que não)".

A pesquisadora novamente retornou a questão: "Ela não pode"?

Eduarda argumentou: "Porque ela é me... 
Significações de um personagem de desenho animado no espaço escolar: um estudo sobre gênero na Educação Infantil

é, é, acha que ele é menina (apontando para o Marcos que estava ao seu lado) ela é menino (apontando para a Mariana que levantou-se)? Acha"? Ela mesma respondeu com ênfase e convicção: "Não. Oh, ela pego o celular de Ben Dez"!

Mariana colocou a mão na cintura olhou para Eduarda e disse com firmeza: "Você não manda na minha vida". Eduarda afastou-se e foi falar com a professora que estava em sua mesa colando portfólios.

\section{Análise}

O episódio aconteceu no espaço escolar da sala de aula dentro de uma determinada rotina, relações e significações, a partir das quais há funções estabelecidas do próprio espaço e como deve ser utilizado pelas pessoas que o frequentam. $\mathrm{O}$ espaço escolar define os tipos de relações envolvidas, a natureza das atividades realizadas, a postura que as crianças adotam, demarcando inclusive as atitudes tomadas nesse episódio.

$\mathrm{O}$ episódio 'O celular', aconteceu logo após o lanche, em sala de aula, enquanto as crianças brincavam com os brinquedos que trouxeram de casa, com os da sala e com os celulares que a professora trouxe para a turma brincar. Eduarda com espanto e indignação aponta para Mariana que estava brincando com um celular dizendo para Marcos que Mariana pegou o celular de 'Ben Dez', um personagem de desenho animado.

A mídia tem oferecido diversos elementos sobre gênero, refletindo no comportamento e nas brincadeiras infantis padrões de feminino e masculino. Sobre o repertório midiático, pode-se afirmar que

Sua presença se estende muito mais do que no momento em que assistem aos programas midiáticos. Povoam o imaginário infantil também pelos usos no cotidiano, ocupando um lugar de destaque em suas culturas, tanto materialmente em suas roupas, fantasias, acessórios, materiais e brinquedos quanto cumprindo um papel importante nas socializações infantis (ODININO; MININI, p. 3, 2011).

No episódio "O celular", o repertório midiático estava presente materialmente em uma figurinha de personagem de desenho animado colado em um celular, fazendo emergir questões de gênero e permeando a interação de algumas crianças naquele contexto.

Nesse episódio, quando Eduarda disse: "Oh Marcos, (olhou para trás onde estava Mariana) ela pego, é, o celular de Ben Dez, (com cara de espanto levou a mão na boca) o de menino", ou quando falou para Marcos com tom de indignação, que ficou olhando para ela sem dizer nada: "Do Ben Dez, oh. Olha lá! Mas essa muié", suas afirmações foram enunciadas sem justificativas, ou questionamentos visto que tinham significado tanto para ela que emitiu quanto para Marcos que recebeu o enunciado, evidenciando que ambos compartilhavam dos julgamentos de valores transmitidos em seus dizeres, através da entonação assim como dos gestos.

Essa questão também fica exposta no momento em que a pesquisadora perguntou: "De quem é o celular do Ben Dez?". Vanessa que estava passando entre a pesquisadora e a Eduarda respondeu junto com Eduarda: "Do menino". Revelando novamente que outras crianças compartilhavam o mesmo julgamento de valor de Eduarda, de que Ben Dez é coisa de menino.

Ao ver que a pesquisadora estava próxima Eduarda a envolveu na situação, dizendo: "Oh tia, sabia que a, que ela (apontando o dedo para a Mariana) uso o celular de, que a Mariana usô, é a Mariana usô o celular do 
Ben Dez do menino", como se estivesse denunciando algo errado que Mariana estivesse fazendo e possivelmente aguardando a interferência do adulto, a pesquisadora, que nesse caso reiterou algumas falas de Eduarda em alguns momentos em tom de pergunta.

Nesses momentos, Eduarda tentou esclarecer para a pesquisadora porque Mariana não podia brincar com o celular do Bem Dez. Essas situações ocorreram quando a pesquisadora reiterou em tom de pergunta: "Do menino?" e Eduarda respondeu: "Porque ela não... ela não pode usa, é celular de Ben Dez, ela não pode (balançou a cabeça indicando que não)".

A pesquisadora voltou a reiterar em tom de questionamento: "Ela não pode"? E Eduarda responde: "Porque ela é me... é, é, acha que ele é menina (apontando para o Marcos que estava ao seu lado) ela é menino (apontando para a Mariana que levantou-se)? Acha?". Ela mesma respondeu com ênfase e convicção: "Não"!

A convicção de Eduarda, que é compartilhada com outros colegas como Marcos e Vanessa, é de que Ben Dez é coisa de menino, por isso uma menina, no caso Mariana, não poderia brincar com um celular com a figurinha do referido personagem de desenho animado. Sobre essa questão não cabe questionamentos, por parte dos envolvidos na situação, pois caso seja, voltase a afirmação Ben Dez é coisa e menino.

Segundo o site, Top Games Kids (2012), Ben Tennyson é um garoto de dez anos que, após um acampamento em família, virou super-herói, pois o Omnitrix, uma espécie de relógio vindo do espaço, grudou em seu pulso. Esse objeto estranho armazena o DNA de dez espécies alienígenas e é capaz de transformar seu usuário em um representante de qualquer uma delas. É claro que tanto poder acarreta em responsabilidade, de modo que Ben precisa salvar o mundo por incontáveis vezes dos alienígenas que pretendem recuperar o Omnitrix. O nome do herói "Ben Dez" advém do seu próprio nome e das dez espécies de alienígenas que ele pode se transformar.

O personagem do desenho animado do "Ben Dez" é um menino, um super-herói que historicamente é representado pela figura masculina, como por exemplo, o "Batman", "O Homem Aranha", entre outros, ressaltando o homem como um ser forte e valente, atributos sociais apresentados como referencia ao gênero masculino, o que é uma ideologia.

Nesse sentido, a associação feita entre a figura do "Ben Dez" ao masculino, foi realizada de acordo com as referências que Eduarda teve acesso, apresentadas pela mídia, e que mantêm relação com os parâmetros estabelecidos socialmente.

Segundo Odinino e Minini (2011), a mídia tem reforçado as diferenças de gênero, promovendo dois universos de consumo, um cor de rosa onde povoam fadas, princesas, bonecas e acessórios de moda, no qual encontram-se elementos que culturalmente caracterizam a feminilidade como a estética da beleza física, a docilidade, a fragilidade e outro de heróis e ambientes de luta, no qual são exaltadas características que remetem à masculinidade como a força, o poder, o desempenho.

A partir das questões ideológicas que o personagem "Ben Dez" traz, a indústria e a mídia reforçam a relação desse personagem ao masculino lançando sandálias, relógios, mochilas do personagem para meninos, o que fica explicito nas propagandas desses produtos que são feitas por meninos. A referência apresentada pela mídia reflete na escolha dos objetos que os pais fazem para seus filhos. Nesse sentido, as crianças podem presenciar em casa o pai comprando uma mochila do "Ben Dez" para o filho, dizendo que é de menino, e comprar de outro 
personagem para menina, justificando que é para meninas.

A ideia do que a mulher ou o homem pode ou não usar, considerando além do objeto em $\mathrm{si}$, mas focalizando aspectos exteriores como cor e forma, é uma construção social e uma prática cultural transmitida pelas imagens, contextos e cenários, assim como pelas falas e vivências da criança em casa e que são trazidos para o espaço escolar.

No episódio, a força dessa ideologia encontra-se presente nas sucessivas falas de Eduarda (e também de Vanessa) junto aos seus pares - crianças que com ela dividiam a cena e o espaço - e também junto à pesquisadora que naquele momento foi alçada por ela à condição de uma interlocutora pretensamente capaz de confirmar seus argumentos em favor da significação por ela manifestada.

Além disso, fica evidente neste referido episódio, uma explicitação das formas pelas quais se realiza no cotidiano o controle das condutas entre pares na qual o "diferente", uma vez significado como inadequado, requer que seja imediatamente posto em conformidade com o tomado como padrão no que tange o comportamento social.

A significação de gênero que emergiu nesse espaço escolar específico, entre os sujeitos envolvidos no episódio, revela, além das significações internalizadas nos contextos mais amplos pelas crianças sobre masculino e feminino, a significação que as mesmas fazem desse espaço.

\section{Considerações Finais}

No presente trabalho apresentamos parte dos dados obtidos em uma pesquisa, cujo objetivo foi investigar como emergem e como se caracterizam os enunciados produzidos pelas crianças, nas suas interações, ocorridas em sala de aula, mediadas pelas atividades propostas pela professora da turma relacionadas a gênero.

A pesquisa realizada em uma instituição infantil, em uma cidade do interior do Paraná, enquanto um espaço escolar físicosocial, permeado pelas relações e ideologias da localidade onde se encontra, apresentou dados que podem ser consideramos próprios desse espaço, pois a maneira como as questões de gênero foram tratadas no episódio analisado, poderia ser abordadas de outra maneira em outro espaço ou por outros sujeitos.

Os dados da pesquisa evidenciaram que, as questões de gênero não estão presentes somente nas relações com crianças maiores ou adolescentes, mas fazem parte também das relações entre os pequenos e estão bastante presentes na educação infantil.

As situações que envolveram gênero emergiram no desenvolvimento das atividades planejadas pela professora da turma e não tinham essa questão prevista, ou seja, não aconteceram intencionalmente, em um momento previsto, planejado com $\mathrm{o}$ intuito de trabalhar a temática.

Durante a realização da pesquisa de campo, as questões de gênero emergiram em momentos de brincadeiras, atividade constante na educação infantil, em que há muitas trocas entre as crianças e que ocorreu em todos os dias, em que se realizou a pesquisa.

Os modos pelos quais as crianças expressaram as questões relativas a gênero foram diversificados, envolvendo além da expressão verbal, gestos, posturas e atitudes que acompanharam a escolha de objetos e modos de brincar.

No episódio "O celular", a discussão envolvendo questões de gênero partiu da escolha de um celular. Entretanto, o objeto em si não é considerado socialmente algo feminino ou masculino, pois homens e mulheres usam celulares.

No uso social do referido objeto o que 
pode ser entendido como distinto para cada gênero são atributos do objeto como a cor, por exemplo, ou, como foi nesse caso, uma figurinha de um personagem de desenho animado, que no contexto infantil tem grande repercussão, tendo em vista, que muitas crianças acompanham desenhos animados em suas casas.

As referências das crianças estão localizadas nos programas veiculados pela mídia em que são apresentadas significações de gênero, a partir de desenhos animados dirigidos ao público infantil, sendo compartilhadas pelas crianças no espaço escolar em diversos momentos inclusive durante a escolha de brinquedos e brincadeiras.

$\mathrm{Na}$ especificidade desse episódio o brinquedo, celular do Ben Dez, foi significado de uma maneira tal que incluía e/ou excluía as possibilidades do brincar dentre os participantes com base no gênero. Pode-se observar que as crianças, ao compartilharem os significados de masculino e feminino no contexto escolar, indicaram as formas sociais hegemônicas relativas ao tema em questão, controlando as possíveis, escolhas e maneiras de brincar dos participantes, mas não somente isso, visto que o comportamento de um membro do grupo simplesmente ignorou essa tentativa de controle.

Nesse sentido, podemos afirmar que o processo de significação não é algo dado a priori, a partir de pressupostos genéricos e situações abstratas. Ele se dá de uma forma singular em cada contexto específico e dependente da forma com que cada um dos agentes participam das relações sociais.

O processo de internalização dos padrões sociais, não está pronto ou acabado e, embora nos deparemos no dia a dia com a força das formas hegemônicas, a continuidade de nossa existência abre, ao menos potencialmente, possibilidades de novas referências que podem resultar em outras formas de significação a depender dos outros espaços de circulação, novos lugares sociais que se venha ocupar e acesso a diferentes práticas culturais neles presentes.

Por serem construídos socialmente, sabemos que há diversos modos de significar o masculino e o feminino em circulação na nossa sociedade e, consequentemente está aberto o espaço para outras formas de significação.

1 A pesquisadora, não tinha a intenção de intervir nos acontecimentos, entretanto, como sua presença se deu por um tempo relativamente grande, as crianças, em certos momentos, se dirigiam a ela a envolvendo na situação.

\section{Referências}

BAKHTIN, Mikhail; VOLOSHINOV. Discurso na vida, discurso na arte: sobre poética sociológica. Tradução para fins acadêmicos de Carlos Alberto Faraco e Cristovão Tezza. In: Freudismo. Trad. I. R. Tiotunik. New York: Academic Press, 1976.

BAKHTIN, Mikhail. Marxismo e filosofia da linguagem. São Paulo: Annablume, 2002.

FELIPE, Jane. Sexualidade, gênero e novas configurações familiares: algumas implicações para a Educação Infantil. In: CRAIDY, Carmem; KAERCHER, Gládis E. (orgs.) Educação infantil: para que te quero? Porto Alegre: Artmed, 2001, p. 61 - 66.

JUNCKES, Ivan Jairo; SILVA, Joseli Maria. Espaço escolar e diversidade sexual: um desafio às políticas educacionais no Brasil. Didácticas Específicas, v. 1, p. 148 - 166, 2009. 
Significações de um personagem de desenho animado no espaço escolar: um estudo sobre gênero na Educação Infantil

ODININO, Juliane Di Paula Queiroz; MININI, Vanda Cristina Moro. A cultura midiática na educação infantil: compartilhando experiências com meninos e meninas. In: 34a. Reunião Anual da Associação Nacional de Pós-gradauação e Pesquisa em Educação, 2011, Natal. Anais da 34a. Reunião Anual da Associação Nacional de Pós-gradauação e Pesquisa em Educação, 2011.

OLIVEIRA, Zilma de Morais Ramos de. Educação Infantil: fundamentos e métodos. São Paulo: Cortez, 2011.

PINO, Angel. Processos de significação e constituição do sujeito Temas em psicologia.v.1, n.1, Ribeirão Preto, p. 17 - 24, 1993.

SCOTT, Joan. Gênero: uma categoria útil de analise histórica. Educação e Realidade, v. 15, p. 05-20, 1990.

SMOLKA, Ana Luiza Bustamante. Construção de conhecimento e produção de sentido: significação e processos dialógicos Temas em psicologia. v.1 n.1, p. 07 - 15, 1993.

SMOLKA, Ana Luiza Bustamante. Conhecimento e produção de sentidos na escola: linguagem em foco. In: Cadernos Cedes. ano XX. n. 35, p. 50-61, julho, 2000.

TOP GAMES KIDS. Conheça as dez transformações de Ben 10 e muito mais. Disponível em:

$<$ http://www.topgameskids.com.br/artigosview/6-ben-10.html>. Acesso em: 22 ago. 2012.

Recebido em 10 de novembro de 2014. Aceito em 05 de setembro de 2015. 